\title{
A musicoterapia como instrumento para mellorar a comunicación de persoas con diversidade funcional
}

\author{
Musicotherapy as a tool to improve communication in functional diversity people
}

\author{
Beatriz López, Berta Fraga \\ Asociación de pais de nenos e persoas con discapacidades das mariñas coruñesas (DISMACOR). Culleredo. A Coruña. España.
}

\begin{abstract}
Resumo
A sensibilidade musical é un trazo innato que implica numerosas rexións cerebrais e que no caso das persoas con diversidade funcional axuda a fortalecer as súas potencialidades e suplir as posibles carencias. No presente traballo selecciónase unha mostra de rapaces con diversidade funcional intelectual que participan nun programa de intervención grupal no que se efectúa unha avaliación final. Os resultados mostran como este tipo de intervencións melloran o desenvolvemento das persoas con diversidade funcional participantes. Este tipo de metodoloxía permiten unha aprendizaxe funcional significativa nunha contorna máis motivante.

Palabras chave: Musicoterapia, comunicación, diversidade funcional, desenvolvemento.
\end{abstract}

\begin{abstract}
Musical sensibility is a innate characteristic that involves numerous cerebral regions and in the case of the people with functional diversity helps to strengthen his potentiality and replaces the possible lacks. In this research we selects a children sample with intellectual functional diversity. We employ a grupal intervention programme to finalice with a sample final evaluation. The results show that this interventions improve general development of this people with functional diversity. This methodology facilitate a functional learning significative in some surroundings more motivating.

Keywords: Musicotherapy, communication, functional diversity, development.
\end{abstract}

\section{Introducción}

A sensibilidade musical é un trazo innato que implica numerosas rexións cerebrais na percepción dos estímulos musicais e a súa elaboración nas emocións que provoca. Á vez a música é integradora en todos os seus aspectos: engloba todos os sentidos, aúna corpo e mente, e fusiona o interior da persoa coa súa contorna. Diversos autores consideran que "a música pode causar cambios no estado afectivo do oínte incluíndo modificacións fisiológicas asociadas con emocións normais" (Allen et al. 2012) cando ao oínte solicítaselle unha resposta verbal á experiencia de escoitala, responderá utilizando termos que dan conta de calquera nivel do espectro de estados afectivos coñecido como emoción.

No caso das persoas con diversidade funcional a música como fenómeno universal, compartido por todas as culturas e presente en todas as épocas, supón un instrumento facilitador. Leo Kanner (1943 citado en Heaton 2009) foi o primeiro en describir a extraordinaria memoria musical presente nas persoas con autismo, informando sobre comportamentos musicais exepcionais. Partindo desta idea Heaton (2009), investiga sobre a capacidade de procesamento musical que posúen os nenos con TEA non savants, en relación ás persoas con desenvolvemento típico.

Outros autores sinalan como os seus “... resultados tamén provén a xustificación neurobiolóxica para o uso das terapias musicais nas síndromes do espectro autista, que parecen resaltar as habilidades emocionais $\mathrm{e}$ facilitar a comunicación nestes pacientes" (Caria et al. 2011). A desviación da atención cara aos compoñentes musicais sucede de forma espontánea e a posibilidade de experimentar fisiolóxicamente os estados emocionais da música constitúena como "un vehículo importante para o desenvolvemento das relacións intersubxectivas favorecendo a atención sostida e á comunicación non verbal" (Quintín et al. 2012 ). Por iso é a música un instrumento idóneo para proporcionar un ambiente rico e controlado en estímulos, achegando unha experiencia sensorial que favorece o desenvolvemento emocional, psíquico, fisiológico e social equilibrado.

Cada un destes propósitos debería ser parte de todo desenvolvemento persoal completo e pleno. Se entendemos saúde como a integración harmónica de todos os niveis da persoa - individual, social, cultural, ecolóxica e medio ambiental - a música como axente socializador proporciona unha situación produtiva, pracenteira, que satisfai, dignifica e inclúe, dando a oportunidade de recoñecemento social e fomentando a autodeterminación e normalización das persoas con 
diversidade funcional, dándolles o seu propio espazo no contexto que lles rodea.

\section{Método}

\section{Participantes}

Selecciónase unha mostra de nenos e nenas pertencentes á asociación DISMACOR. Unha parte do grupo presenta carencias en relación coa socialización e comunicación áreas, onde a Musicoterapia actúa de forma especial. O grupo está conformado por suxeitos con algún tipo de diversidade funcional (Atrasos de diferente tipo $(16,6 \%)$, TEA $(83,4 \%)$. En relación ás idades o 49,8\% correspóndese con suxeitos de 4-6 anos, o $33,2 \%$ de 9 a 17 anos e o $16,6 \%$ maiores de 11 anos. No relativo ao xénero dos participantes, o $33,2 \%$ son femias e os $66,8 \%$ homes. O tipo de escolarización é ordinaria no $33,2 \%$ e combinada no $66,8 \%$ dos casos.

\section{Obxectivos}

O obxectivo fundamental da intervención é o desenvolvemento completo de toda persoa, tentando fortalecer as súas potencialidades e suplir as posibles carencias, ámbito onde a música é un instrumento que motiva e dinamiza, creando un ambiente de seguridade e confianza que posibilita o traballo de diferentes obxectivos, como son:

- Mellorar as relacións interpersoais. Participación e aceptación do grupo como elemento socializante.

- Estimular mediante a memoria, atención, reflexión e en xeral, as facultades intelectuais.

- Desenvolver as facultades psicomotoras (coordinación, esquema corporal, lateralidade...)

- Desenvolvemento da autoestima e confianza en si mesmo

- Compensar os problemas de incomunicación, mellorar e desenvolver a expresión verbal e a linguaxe.

- Desenvolvemento da percepción sensorial e estética.

- Estimulación e desenvolvemento da fantasía, imaxinación e creatividade.

- Gozar do pracer estético. Espertar os sentimentos de alegría, satisfacción e sensibilidade.

Para realizar o programa efectúanse intervencións grupais cunha duración dunha hora semanal ao longo de 9 meses. Ademais utilízase un cuestionario final de valoración no que se recollen datos relativos á relaxación, satisfacción, comunicación, socialización, estado de ánimo, autonomía, psicomotricidade, autoestima e creatividade.

\section{Procedemento}

Efectúase un programa de intervención grupal mediante o que se traballan aqueles aspectos onde se detecten maiores necesidades de apoio, para pasar posteriormente a unha avaliación final da mostra.

\section{O programa de intervención.}

O programa emprega pictogramas para secuenciar os pasos e facilitar a comunicación ás persoas participantes. Este programa conta coas seguintes actividades tipo:

Canción de Benvida: saúdo a todos e cada un dos membros do grupo, un por un, de forma que se lles fai conscientes e partícipes do inicio da sesión, dando pé a que mostren o seu estado nese intre. Cada un ten o seu momento de intervención na canción, onde se trata de que participe na medida en que sexa posible (movemento, palabra, balbuceo, sons, palmadas...).

Actividade instrumental e/ou vogal estruturada: realízase a través de diferentes actividades, que van desde a participación activa do grupo, tocando eles mesmos os instrumentos; até a audición de música pregrabada.

Expresión corporal: actividades con máis contido motor, onde se porán en marcha diferentes dinámicas que desenvolverán a toma de conciencia corporal.

Relaxación: orientada, tanto ao repouso necesario polo movemento da sección anterior, como á toma de conciencia corporal.

Canción de despedida: como peche de sesión despídese a todos os participantes.

Posteriormente e tras 40 sesións dunha hora efectuadas en grupos reducidos, procédese a unha avaliación final do grupo.

\section{Resultados}

O emprego da música como ferramenta nas persoas con diversidade funcional permite acadar avances en diferentes áreas do desenvolvemento. A continuación recóllese nunha táboa os resultado obtidos neste proceso.

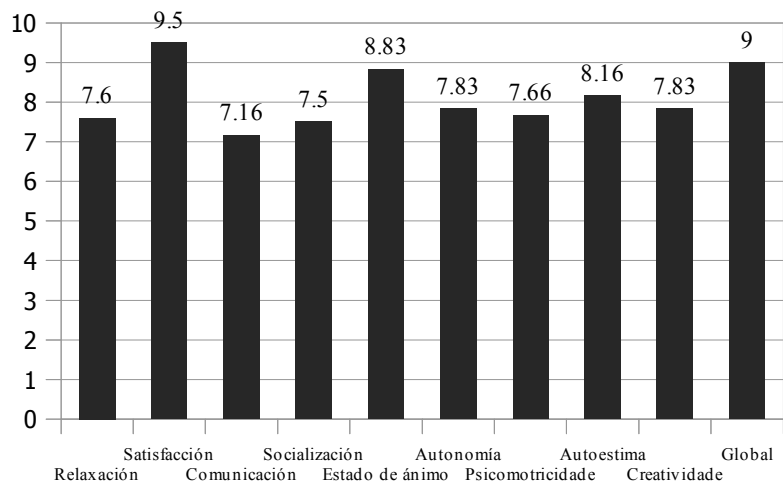

Figura 1. Puntuacións recollidas na avaliación final do programa. 
$\mathrm{Na}$ valoración cualitativa do programa as familias comentan que as actividades máis valoradas son as relacionadas co baile e os instrumentos de percusión. Os beneficios que se destacan son en relación a socialización, melloras no estado de ánimo, relaxación, atención e control de emocións. Todas as familias indican que este programa tivo repercusións positivas nas persoas con diversidade funcional, están satisfeitas co seu deselvolvemento e teñen previsto volver a participar nas seguintes convocatorias.

\section{Discusión}

A música ofrece unha motivación natural na persoa con diversidade funcional. A desviación da atención cara os compoñentes musicais sucede de forma espontánea e a posibilidade de experimentar fisiolóxicamente os estados emocionais da música propicia chegar ás persoas establecendo vias para o seu desenvolvemento.

A música facilita que as persoas con diversidade funcional podan relacionarse cos demais, propicia que presten maior atención ás distintas tarefas que se lle presentan e podan expresarse mediante outra linguaxe que non é a verbal, habilitando unha nova forma de mellorar a calidade de vida destas personas e constituindo á musicoterapia como unha ferramenta privilexiada a considerar nos programas de intervención.

\section{Referencias}

Allen, R., Davis, R. e Hill, E. (2012). The effects of autism and alexithymia on psycologucal and verbal responsivness to music. Journal of autism and dev. Disorder. Publisher Sprinter US vol 43 issue. 2 pp.432 $-444$.

Caria, A., Venutti, P. e De Falco, S. (2011). Funcional and disfunctional brain circuits underlying processing of music in autism spectrum disorders. Cerebral cortex dic $2011 n^{\circ} 21$ pp 2838-2849.

Heaton, P. (2009). Assessing musical skills in autistic children who are not savants. Journal of philosophical transactions of the royal society $B$ biological sciences. abril $2009 n^{\circ} 364$ pp 1443-1447.

Quintin, E., Bhatara, A., Poissant, H., Fombonne, E., e Levitin, D. (2013). Processing of musical structure by high-functioning adolescents with autism spectrum disorders. Journal of child neuropsychology vol $19 \mathrm{n}^{\circ} 3$ 250-275. 